\title{
God As Both Ideal and Real Being In the Aristotelian Metaphysics
}

\author{
Martin J. Henn \\ St. Mary College
}

Aristotle asserts in Metaphysics $\Gamma, 1003 a 21 f f$. that "there exists a science which theorizes on Being insofar as Being, and on those attributes which belong to it in virtue of its own nature."' In order that we may discover the nature of Being Aristotle tells us that we must first recognize that the term "Being" is spoken in many ways, but always in relation to a certain unitary nature, and not homonymously ( $c f$. Met. $\Gamma, 1003 a 33-4$ ). Beings share the same name "غ่ó $v \tau \alpha$," yet they are not homonyms, for their Being is one and the same, not manifold and diverse. Nor are beings synonyms, for synonymy is sameness of name among things belonging to the same genus (as, say, a man and an ox are both called "animal"), and Being is no genus. Furthermore, synonyms are things sharing a common intrinsic nature. But things are called "beings" precisely because they share a common relation to some one extrinsic nature. Thus, beings are neither homonyms nor synonyms, yet their core essence, i.e. their Being as such, is one and the same. Thus, the unitary Being of beings must rest in some unifying nature extrinsic to their respective specific essences. Aristotle's dialectical investigations into Being eventually lead us to this extrinsic nature in Book $\Lambda$, i.e. to God, the primary Essence beyond all specific essences. In the pre-lambda books of the Metaphysics, however, this extrinsic nature remains very much up for grabs.

In Metaphysics $\Gamma$ Aristotle refers to beings as "things spoken

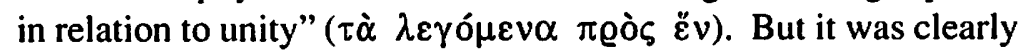
established in Metaphysics B,998b22ff. that beings are not members of a summum genus. If they were, they would be spoken $\kappa \alpha \theta^{\circ} \varepsilon \check{\varepsilon} v$, or "under a unity." The reason why Being is no summum genus is that, if it were, its essence would repeat itself in the differentiae dividing it into subspecies (cf. Met. B 998b22ff. \& $H$ 1045b6). Consider the genus Animal. If we divide animals into their various species according to habitat (as fundamentum divisionis) we might 
employ the differentiae terrestrial (i.e. dwelling on land), aquatic (i.e. dwelling in the sea), and aerial (i.e. dwelling in the air). These differentiae neither imply nor rely upon the generic concept Animal; if they did, the division would be logically inadmissible. Now if we were to divide Being by taking it as a summum genus resoluble into species by means of the categories (understood as differentiae), we could never avoid implying the concept of Being in our deployment of the differentiae; for we understand Being in terms of being-a-substance, being-a-quantity, being-a-quality, etc. In other words, the differentiae would, in this case, fail to differentiate Being into beings.

We know that Being is not a genus; but at the same time we know that Being is universal quite like a genus. We know that beings are spoken in relation to some unitary nature; but we neither know what this nature is in itself, nor are we in possession, as yet, of a sound scientific method for identifying this nature. All we know is that there is an $\dot{\varepsilon} \pi \imath \sigma \dot{\eta} \mu \eta$ of Being, and that this fact

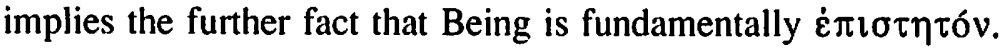
There is in the concept of Being qua Being a knowable core structure around which fruitful discourse can be shaped. But we need to know what kind of universal Being is, before we can begin to unfold the richness of its meaning.

Fortunately Aristotle provides us with two scientific methods for discovering the richness of Being: (1) dialectical term analysis and (2) division by analogy. Analogy comes into play scientifically, as we are told in Posterior Analytics 98al-23, when division by genus is not possible. Analogy is an alternative method for dividing the subject of investigation when no clearly definable genus is recognized for objects of diverse natures. This is precisely the case for beings understood as "things spoken in relation to unity." For instance, Aristotle claims in Posterior Analytics 98a20-22, that analogy is used for discovering a certain unitary nature shared by the cuttle-fish's pounce, the spine of an animal, and a bone - three things for which there is no common name. "Attributes will follow from [these three] as if belonging to a certain unitary nature, being of such a sort." Aristotle even recycles the Analytics phrasing

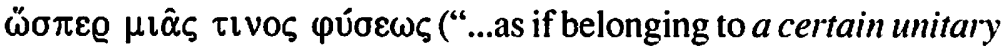
nature...") in Metaphysics $\Gamma 1003 a 34$ when he says that the many 


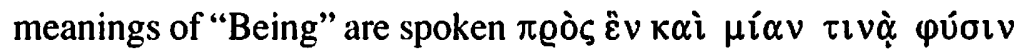
("in relation to unity and a certain unitary nature"). Since Being is not a genus, investigation into the nature of Being must proceed analogically.

I propose to examine here the conditions under which Aristotle's analogical investigation of Being is possible as science. What is it that makes the investigation of Being qua Being feasible scientifically, given the dialectical precondition which Aristotle himself sets out in Metaphysics $\Gamma 2$, inter alia, for finding a focal meaning or primary Being? In other words, does Aristotle successfully discover a suitable focal meaning for 'Being'? And if so, what is this primary Being? Is it primary ovoi $\alpha$ as discussed in the central books, $\mathrm{Z}$ and $\mathrm{H}$ ? Does it involve the notions of actuality and potentiality considered in $\Theta$ ? Or does it revolve around a dialectical treatment of unity-in-itself, as suggested in $\Gamma$, reevaluated in $\mathrm{K}$, and analyzed in $\mathrm{I}$ ? Or does Aristotle's concept of Being involve all of these?

Certainly each strain of analysis represents a viable candidate. The medieval schoolmen even held a special place for the concepts such as being, one, whole, good, etc. They treated them as highest universals. ${ }^{2}$ And they bestowed upon these concepts the privileged appellation "transcendentalia" in the sense that they "ascend beyond" Aristotle's list of categories, remain predicable of beings across categories, and are not to be contained under any one category exclusively.

I propose here to show that while there is substantial evidence to back the legitimacy of substance, unity, and actuality as accounting for the nature of Being insofar as Being, Aristotle nevertheless radically reassesses their claim to primacy in Metaphysics $1,4 \& 5$. I also propose to account for why Aristotle recanted his position on the feasibility of universal science in Metaphysics $\Gamma$. In the Organon he manifestly discounts the possibility of a universal science of Being. While during the composition of the Metaphysics he asserts that such a science actually exists, as if there were never a problem about its feasibility.

Scholars in the last half of this century have been divided over the issue of feasibility. T. H. Irwin, for instance, emphasizes Aristotle's own denial of universal science in the Organon. Irwin 
thinks that Aristotle's rejection of one comprehensive science of the good (E.N. I 6 1096a29-34) unavoidably infects the feasibility of one comprehensive science of Being:

At Topica 107a3-12 (cf. Ethica Nichomachea 1096a23-9, Ethica Eudemia 1217b26-38, Ackrill [1972], 21f) Aristotle argues that goods are homonymous because goodness differs according to the different categories of being; it is hard to believe that he does not intend, here as elsewhere, to mark a similar homonymy in beings. . . Just as the question 'What is it?' requires a different type of answer according to the category of the item considered, so also the statement ' $x$ is $F$ ' must be understood differently according to the category of $x$, and being will be defined differently according to the categories. ${ }^{3}$

Other scholars, especially G. E. L. Owen, show that Aristotle eventually amended his claims in the Metaphysics. Owen argues that Aristotle's new found application of 'focal meaning analysis' in the Metaphysics is responsible for this change:

In Metaphysics I 992b18-24 he says that because of this variety in the use of 'onta' it is a mistake to engage in a general search for the stoicheia ton onton ('elements of existing things', Oxford translation). In Metaphysics XIV, 1088b35$1089 \mathrm{b3} 3 \mathrm{he}$ argues this thesis at length (concerning 'existing things' or 'things that are', O.T.). In the Eudemian Ethics I (1217b25-35) he maintains that the same multiplicity shows that there can be no single comprehensive science of to on ('being', O.T.). In Metaphysics IV (1003a21-b 16), resuming the same subject, he amends his claim: despite this multiplicity of use there can be a single comprehensive science of to on and ta onta, and those who looked for the elements of ta onta were very likely on the track of this science. ${ }^{4}$ 
Owen's contribution, valuable and original though it is, misses the fact that Aristotle had already placed analogical investigation shoulder-to-shoulder with division by genus as an equally legitimate scientific method of discovery in the Posterior Analytics 98al-23 long before he composed the Metaphysics. Owen does not adequately account for the cause of the workability of this new found application of focal meaning analysis (in Metaphysics $\Gamma$ ) because he overlooks God as the much-needed linchpin between universal and particular. Aristotle's God represents both (1) the primary Being, and (2) a universal ideal applicable in formula to all beings. God is both that into which all beings collapse qua beings, and that out of which all beings derive their essence as beings. This makes Aristotle's God both ideal and real, both transcending the beings of this world, and disclosing essence in the beings of this world.

In the works comprising the Oraganon, however, Aristotle does not apply focal meaning analysis to 'Being' - even though he had fully worked out the dialectical mechanics of term analysis because he had no theological basis for regarding the concept of Being as any thing more than an indeterminate cipher; in other words, he saw Being universally as nothing particularly, and therefore as not worthy of scientific investigation. For instance, he asserts in his refutation of the sophists that "...we ought not attempt to grasp the number of things against which those who refute do their refuting without scientific knowledge ( $\dot{\varepsilon} \pi \iota \tau \tau \dot{\eta} \mu \eta)$

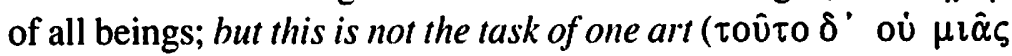

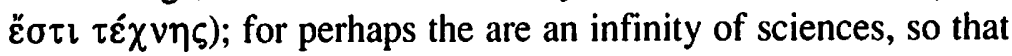
obviously there would be an infinity of demonstrations as well (Sophistici Elenchi 170a20-23)." This tone is repeated in Sophistici Elenchi 172al3-15 where he denies that all beings fall under one genus - a position he would maintain in the Metaphysics as well (cf. 998b22, 1045b6) - and again at De Interpretatione 16b22ff. where he claims that unqualified Being is an indeterminate abstraction significant of nothing in particular, on the grounds that when "is" is used without accompanying predicate, it signifies nothing at all.

In the Metaphysics, however, his attention turns to Being. What was once regarded in the earlier phase of his career as unknowable, 
vacuous, and indeterminate through-and-through turns out to be, in the Metaphysics, that which the Philosopher asserts to be fundamentally $\dot{\varepsilon} \pi \iota \sigma \tau \eta o ́ v$. Owen portrays Aristotle composing Metaphysics $\Gamma$ as having "returned to, or newly arrived at, a belief in the possibility of a general metaphysics after a period in which he had denounced any such project as logically indefensible and castigated Plato and the Academy for pursuing it."' Aristotle claims in the Metaphysics that there is a universal science of Being which is different from the so-called special sciences "for none of the others examines universally about Being insofar as Being (1003a23)" and also that "...it belongs to one science to theorize not only on things spoken kầ

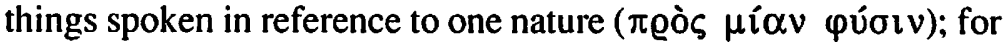
these too are, in a way, spoken of $\kappa \alpha \theta^{\circ} " \check{\varepsilon} v^{\prime \prime}(1003 b 12-15)$. In the

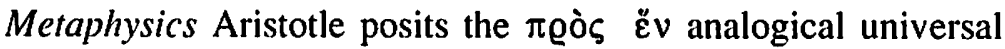
"Being" to be a legitimate object of scientific investigation; nevertheless, the analogical method of investigation employed to contemplate the universal had already been long established as legitimate scientific procedure in the Posterior Analytics. As Professor Horst Seidl recently remarked at a recent gathering of the Society Aristotelica Jannone, the scientific method of investigation and exposition pioneered in the Analytics is applied through-and-through to the Science of Being developed in the Metaphysics. What changes between the composition of the Analytics and the Metaphysics is not Aristotle's attitude about division by analogy, but his attitude about Being as such. The cause of this change appears to be his discovery of God.

If Aristotle's God is the focal Entity, the reduction of the many meanings of the term "Being" to God will be comparable to the many meanings account of $\varphi \imath \lambda i \alpha$ given in Ethica Eudemia VII 2 where the various senses of 'Friendship' are reduced to one primary kind. ${ }^{7}$ The following passage describes in detail how three different forms of friendship (one motivated by utility, another by pleasure, and another by excellence, $1236 a 36-1236 \mathrm{bl}$ ) are related to one central meaning or primary form, but not through an ordinary $\kappa \alpha \theta^{\circ}$ $\varepsilon \ddot{\varepsilon}$ reference, nor through chance homonymy, but through $\pi \varrho o ̀ \zeta$ $\ddot{\varepsilon} v$ reference: 
Therefore, there must be three kinds ( $\varepsilon i \bar{\eta} \eta$ ) of friendship, but not all so termed under one thing

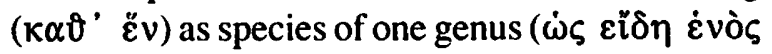
$\gamma \varepsilon \dot{\varepsilon}$ ous), nor as sharing a name homonymously. For these kinds are spoken relative to a unitary

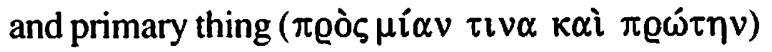
(EE 1236a 16-19, my translation)

Aristotle consciously employs the same dialectical procedure in his analysis of 'Being' in the Metaphysics. Look again at this passage from Metaphysics $\Gamma$ :

The term "Being" is spoken in many senses, but in reference to some unitary nature, and not homonymously - just as every healthy thing refers to Health, one thing by guarding it, another by producing it, another by being a sign of Health, and another by admitting of it (Met. 1003a33-b1).

These two cases of term-analysis are so similar, in fact, that they

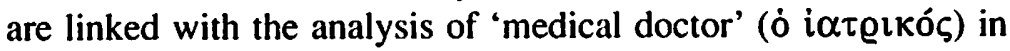
the Ethica Eudemia 1236al9. The dialectical method in all three cases remains constant: there is an abstract unspecifiable universal (e.g. Friendship, Medicine, Being) whose essence is to be discovered through analogical reasoning. A primary archetype is posited so that the universal's abstract and nebulous nature may be contemplated in more concrete terms (e.g. the model friend who loves you for who you are and not for pleasure or utility, the medical doctor with medical knowledge in his soul, and God, the primary Being). Finally, the formula of this archetype must be sought in the formulae of all relevant $\pi \varrho o ̀ \varsigma \check{\varepsilon} v$ relata. The formula of the archetype represents an identity of essence within a prevailing difference of function and species among the relata.

As we have mentioned, there was a time when Aristotle did not countenance this application of focal analysis to the term "Being." For instance, at Ethica Eudemia 1. 8, 1218a34-6 that which is Good-in-itself is concluded to be of no value for political science, and is asserted not to exist. ${ }^{8}$ It is the case, argues Aristotle, 
that each science has value because it produces a peculiar good; gymnastics, for instance, produces physical health. By analogy only peculiar individual beings exist. There is no Being-in-itself. Aristotle regards the Good in abstracto, and by extension Being, as too indeterminate to have any scientific value, to merit serious scientific attention. G.E.L. Owen, however, lays too much emphasis on the priority of ousia in Metaphysics $\Gamma$, and too little on the role of God in $\Lambda$. "It is $\Gamma$, not $\Lambda$," claims Owen, "that moves decisively beyond the old polemic, the denunciation of any general inquiry into the 'elements of things' which is still audible in Metaphysics A." Owen says that "in the earlier work <e.g. the Sophistici Elenchi and Eudemian Ethics $>$ that ambitious application [of focal analysis to 'Being'] is still to seek." 1 And he is right to record this fact. But he leaves the role of God as archetype of Being out of his account, and places too much emphasis on the priority of substance in Met. $\Gamma, Z, H$, and $\Theta .{ }^{\prime \prime}$ Because God is, in a sense, both one thing and all things, He can serve as both (1) the $\tilde{\varepsilon} v$ which all other beings are $\pi \varrho \delta \zeta$, and (2) the concept whose formula (to apply a standard of focal analysis already established earlier in $E E$ 1236a 1236a 16-33) must be present implicitly in the formula of all beings. This dual quality is absent in primary ovoí $\alpha$. Primary

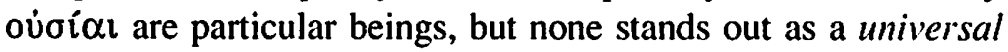
primary archetype. Socrates, for example, is a primary ovioi $\alpha$, but not the primary oujoi $\alpha$.

Thus, the idea that Aristotle simply changed his mind about the feasibility of ontology as he matured in his philosophical career is well documented, but incomplete. He changed his mind because he discovered God. It is not strange to find passages, especially in the Topics, Sophistici Elenchi, and De Interpretatione which shoot down the idea of a comprehensive science of Being due to a multiplicity of senses, or to an implicit marriage of reality with radical particularity, or because of a supposed inability of science to bring all beings under the same set of principles or the same genus. ${ }^{12}$

Look again closely at de Int. 16b22ff., for instance. Aristotle asserts that a verb, uttered just by itself, signifies an activity unfolding over time. When it is spoken the speaker arrests his thought while the listener pauses, awaiting completion of the verbal 
idea. But it is not clear whether this activity exists or not "for not even the verb 'to be' nor 'not to be' is significant of any reality, not even if you say 'Being' without any qualification ( $\psi \imath \lambda \operatorname{ló}^{\mathrm{v}}$ ); for in itself it is nothing, but signifies some synthesis besides, which, without its constituents, is not to be thought."13

To be, according to this passage, is to be essentially relative to and dependent upon determining qualities. When one speaks of Being $\psi \mathrm{\imath} \lambda \hat{\alpha} v$, as Aristotle does in the passage quoted, one has in mind existence in bare abstraction. Being, taken $\psi \imath \lambda{ }^{\circ} \nu$, is bare to the world, much as a soldier is bare without protecting armor, or a bird stripped of its plumage, or poetry sung without the accompaniment of music. Such bare, unadorned Being does not signify any reality determinable through the categories. For Aristotle, at this stage in his philosophical development, Being in itself (qua Being) is significant of nothing in particular. And it is just this facet of indeterminability that Aristotle challenges in Metaphysics $\Gamma$. There, it seems, "Being qua Being" is another way of expressing Being understood $\psi \imath \lambda$ ó $v$ (though he does not use this adverbial modifier in $\Gamma$. And this unqualified form of Being is at least determinable through necessary logical laws. Being understood $\psi \imath \lambda$ óv, in other words, evolves into the "unqualified Being" which is said, in the context of Metaphysics +. 2, 1026a33,

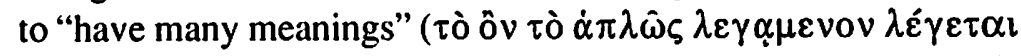
$\pi 0 \lambda \lambda \alpha \chi \hat{\omega} \varsigma)$. The question that we have been trying to answer is this: How does the term "Being" come to acquire such a rich significance in the Aristotelian metaphysics, when before it possessed no significance at all? How does bare unqualified Being, for which no meaning nor reality can be found in De Interpretatione 16b22-25, inter alia, transform itself, in the Metaphysics, into that which is $\lambda \dot{\varepsilon} \gamma \varepsilon \tau \alpha l$ ro $\pi \lambda \alpha \chi \hat{\omega} \zeta$ ? How does 'Being' become a dynamic concept with a multiplicity of meanings and senses open to philosophical analysis and speculation?

We can surmise that Being maintains a radical simplicity isolated from the particular determinations of the categories. And it seems that the turn Aristotle's thinking takes in the Metaphysics comes in seeing this simplicity as a positively definable set of attributes which manifests itself concretely in a self-absorbed God always busy thinking of Himself, and analogically as primary ousia, 
as potentiality becoming actuality, as a substratum continually changing between contrary states. In the Organon, however, especially in the passage from DeInt. 16b22f., this same simplicity of Being = sheer negation, a cipher, precisely that which cannot be thought or made sense of because not classifiable under a category. In Met. $\Lambda$, however, there is God. Yet even God appears classifiable under the category substance; though his existence transcends the categories. But how is this so? How can God's essence both transcend the categories, yet be contained under the category substance in much the manner that the essence of Socrates (rational animal) is contained? The answer must be that Aristotle's God maintains both an ideal essence and a real presence in all things qua beings. God is the Being of beings, both real and ideal simultaneously, both in and out of our world of sense experience.

In the (early) Organon phase Aristotle maintained a position of ontological nihilism: Being universally is nothing particularly. The difference in Aristotle's attitude toward Being, and toward the feasibility of its systematic study, between the time he writes the works of the Organon and $S E$ and the time he composes the opening books of Metaphysics $\Gamma$ clearly reflects a fundamental shift in standpoint. Regardless of the chronology of the works at issue, it still holds that the philosopher changed his mind. At $S E$ 172a13-15 he denies that beings fall under one genus. He goes on to claim that, even if they did, they could never be brought under the same set of principles. Yet in a different phase of his career Aristotle claims that previous thinkers might just be right in asserting that all things are either contraries of composed of contraries, and One and Many are the principles ( $\alpha \varrho \chi \alpha i)$ of all contraries. ${ }^{14}$

C. A. Kirwan, by contrast, suggests that $M e t . \Lambda 10.1075 \mathrm{a} 28-$ 34 provides evidence that Aristotle rejected the opinion, held by practically everyone at the time, that the physical world is composed out of contraries. Kirwan even thinks that the 1005a3-5 passage from Met. $\Gamma 2$ represents an ad hominem statement, in spite of the fact that Aristotle gives absolutely no indication that he is taking issue with the idea, and the fact that it enhances rather than detracts from the science which he is trying to construct. ${ }^{15}$ 
The fact is that Aristotle was intrigued with contrary forces in nature. In the Physics, for instance, he develops a science which studies contrariety in application to kinetic change, i.e. qualitative alteration, quantitative growth $\&$ diminution, and locomotive change (v. Phys. 225b5-6b17). Each of these classes of movement are changes between contraries. Contrariety informs the motion of beings. How could this be the theory of a man hostile to the idea that the physical world is composed of contraries? Aristotle simply adds a substratum to the contraries. Change occurs in a substratum between state and privation. But contrariety remains essential to physical explanation. And all things may be composed of contraries once these contraries are understood to be principles and causes of our knowledge of reality; as opposed to material causes of things. Many of Aristotle's predecessors made the mistake of conflating these two types of cause.

Furthermore, a closer look at the context of Kirwan's supporting text, Met. N 1075a28-34, reveals that Aristotle, rather than taking issue with the notion that contrariety pervades all things, is really disagreeing with the fallacious views of those who make one contrary the matter upon which the other contrary is to rest as form. Principally, he chides those who make the unequal matter for the equal, and those who make the many matter for the one. Aristotle rejects these blueprints in favor of an underlying matter independent of the contraries, yet receptive of formal change along a continuum of qualitative degree of difference stretching from one contrary quality to another.

Kirwan's other supporting text, Met. $N$ 1087a29-b4, does not show Aristotle rejecting the view that the physical world is composed of contraries, but rather the view that contraries are somehow capable of separate existence. Aristotle rejects this possibility along with separately existing (Platonic) Forms. The Form is universal; and, for the Platonists, maintains a other-worldly existence separated off from the particular individuals which embody them. For Aristotle, the universal expresses itself in the particular individual. In other words, the ideal Form realizes itself (i.e. makes itselfreal) in all of its particular embodiments. Platonists believe in ideal Forms which may or may not claim embodiment in the particular; thus, Form is separate from matter. For Aristotle, 
the ideal Form can not exist save insofar as it makes itself to stand in the particular. Now the fact that Aristotle's universals and forms maintain their existence in the individuals of this world, i.e. exist insofar as they are instantiated in concrete particulars, does not mean that science lacks universal principles as starting points, it just means that these starting points do not have separate existence. Kirwan probably misreads Met. $1087 \mathrm{a} 29-\mathrm{b} 4$ as a statement of Aristotelian doctrine against any universal ontology which would take the One and Many, or some other set of universal principles as starting points. Nothing could be further from the truth. Again, what Aristotle is rejecting in this passage is much the same idea that he rejects at 1075a28-34: that contraries somehow exist independently and separate from the underlying subject.

In sum, Kirwan overlooks that, for a short time, Aristotle entertained the view that the contrariety of Unity v. Plurality formed co-relative principles of ontology. The passages we have in $\Gamma$ are tentative and experimental. In fact, Aristotle departs from the path of Unity by choosing the path of primary ousia in the central books, then moves on to potency in act, and then finally, rejecting all three strands of analysis as mere analogy, goes on to prove the unity, substantiality, and actuality of God in Met. $\Lambda$. In other words, the three strands of analogy are dovetailed as primary attributes of the supreme Being.

Aristotle simply had not developed the notion of God, i.e. primary Essence, understood as the Ideal realizing itself in the specific essence of individuals, early enough in his career to allow him to apply focal analysis to "Being" in a workable format. Without God there would be no cosmic basis of permanence upon which to ground the Science of Being. This notion of God as primary essence - a supreme Being whose formula is necessarily present in the formulae of all beings, qua beings - allows Aristotle's new found application of focal analysis in Met. $\Gamma$ to flourish. Aristotle does not begin Metaphysics $\Gamma$ with discussion of God, but rather with an abstract and seemingly indeterminate notion of Being as such. He then slowly adds layers of determination to it by experimenting first with necessary logical laws $(\Gamma 3-8)$, elements of primary substance (E 2-H), and the notions of actuality and potentiality $(\Theta)$. He then arrives at God as "that which imparts 
motion without being moved, being eternal, substance, and actuality"'6; i.e. God is a primary essence, a focus of meaning, which gives concrete existence to the abstract notion of Being as such. This development is radical indeed. Being qua Being is abstract, but God is concrete. Being qua Being is determined through equally abstract logical laws; but God is palpable and alive, self-aware, and forever actual, though impersonal, self-absorbed, and distant. The Metaphysics begins in $\Gamma$ with the unspecifiable notion of Being, explores a multitude of meanings of Being, then ends in $\Lambda$ with the assertion of God's radical oneness, and the Homeric line:

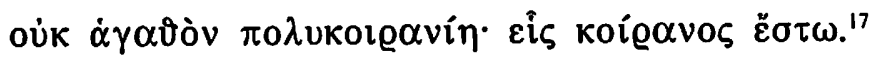
Rule by the many is no good. Let there be one ruler.

The emphasis here is clearly on the one beyond the many. To understand what beings essentially are, qua beings, we must examine a God which transcends the beings of this world.

But Aristotle's assertion that God is an immaterial "primary essence" (Met. $\Lambda 8,1074 a 35-6)$ sounds suspiciously like the Platonic assertion of separate immaterial Forms. And it is likely that God is the one exception Aristotle grants to his general ban on separately existing ideals. Joseph Owens regards Aristotle's God as a primary instance universal (cf. 'An Ambiguity in Aristotle, EE VII 2 1236a23-4' Apeiron, vol. XXII, no. 2, June 1989, pp. 127-137; 'The Grounds of Universality in Aristotle', American Philosophical Quarterly, vol. 3, no. 2, April 1966). But how, one must ask, can God be an instance of any concept or idea? If God is an instance of Being, albeit the "primary" one, the concept of Being would possess a richness beyond God, since other beings also instantiate Being, and thereby amplify its meaning. I argue that God = Being qua Being. God's essence, therefore, transcends categorization, but, at the same time, rests implicitly within the essence of worldly finite entities, qua entities. Worldly entities, e.g. Socrates, Callias, this reed stalk, etc., are, like God, actual unitary substances. But God is not merely a substance; He is substance itself. God is not merely an actualization; He is actualization itself. God is not merely $a$ unity; He is unity itself. 
God, in other words, is individual only in the sense that we make assertions about $\mathrm{Him}$ as a subject having certain attributes. An archetype can not be an instance of any concept, lest we suppose that concept to be prior in knowledge to said archetype, having a richness of meaning which outpaces the archetype.

On the other hand, Owens may mean that God is a primary instance universal in the sense that God represents a locus of meaning for beings, qua beings. This notion warrants consideration. The meaning or significance of a term like "Being," "medicine," or "health" is unspecifiable, since none is a genus, yet there remains a primary entity in which the significance of each term is idealized. However, God is different from the healthy body and the medical doctor, since God exists independently from the beings of this world, whereas the healthy body and the medical doctor are to be found among the beings of this world.

In the case of "Being" the primary instance is an idealization which explicitly transcends the things of this world, yet remains in them insofar as its formula is implicit in the formula of every being. In the case of "medicine" and "health" the primary instance is any immanent realization which embodies either concept respectively. The way to understand what makes instruments, bodies, and operations "medical" is to study the art of medicine which any medical doctor has in his soul. To study what makes things "beings" is to study the supreme Being, not just any being. Strictly speaking, there is no supreme medical doctor which exists independently of medical things, while there is a supreme Being which exists independently of beings.

There is a similarity between analysis of the terms "Being" and "medicine." Just as any doctor represents the nucleus of meaning for medical instruments, operations, and bodies, so God represents the nucleus of meaning for beings. This nucleus of meaning is primary; things whose nature is parasitic on it are secondary. Think of Aristotle's virtue-based ethics and the point becomes clear. The moderate state of behavior is optimal and virtuous, but one may easily stray from moderation through certain excesses and deficiencies. For instance, courage is a mean between rashness and cowardice; modesty is a mean between shamelessness and diffidence. The mean is a model of excellence; it is that in 
reference to which the extreme forms of behavior, the excesses and deficiencies, are known, and possibly corrected. And he who acts according to moderation is a model of virtue. But there are as many models of virtue as there are virtuous people. There is only one model of Being; and this is God.

Aristotle's pedagogical program in the pre-lambda books of the Metaphysics is to furnish a dialectical propaedeutic for students in need of templates of argument for both sides of some of the foundational questions of first philosophy. When God is brought into the picture, first philosophy is identified as theology and Aristotle's universal science becomes feasible as study of the divine nature. The reason why ontology (i.e. being-study) can only flourish as theology is given by the distinction already highlighted. Actuality, substance, and unity are universal concepts, but none is primary by itself without a supreme Being which exemplifies them in the highest degree. That is, there are a plethora of worldly beings that are actual, substantial, and unitary - but none is a primary instance by itself; just as there is no single medical doctor or healthy body which can claim primacy over other equally excellent doctors and healthy bodies. Thus, Aristotle's dialectical application of focal meaning analysis to the term 'Being' inevitably and necessarily results in a Theology which studies a separately existing Prime Mover or God, that transcends the beings of this world. If there existed a singular ideal Doctor or a singular ideal Healthy Body, then medicine and the study of health would also be first philosophies!

What makes first philosophy first among the sciences without qualification is that it studies the Prime Mover who exemplifies, in the highest degree, the analogical notions of substance, actuality, and unity. Aristotle proves this fact by demonstrating three truths in Metaphysics 1 : (1) that there exists in eternal substance, a Prime Mover (1071b3-12); (2) that this Prime Mover is a principle whose substance is actualization (1071b12-22); and (3) that the Prime Mover is one both in formula and in number (1074a31-38). At Met. $17,1072 \mathrm{a} 26-\mathrm{b} 1 \mathrm{God}$, identified as supreme object of desire, is said to be intelligible through the notions of substance, actuality, and simplicity (i.e. unity without parts) each of which represents a positive notion in Aristotle's double column of contraries. ${ }^{18}$ This 
double column recalls another series of contraries mentioned in $\Gamma$ 2. The interconnection of these texts is vital to Aristotle's entire dialectical project, because $\Gamma 2$ sets up the dialectical requirement for a focal entity whose identity as God is not deduced until $\Lambda 6$. Once the focal entity is demonstrated to exist, the dialectic over the many senses of the term 'Being' comes to an end. All secondary senses and instances of 'Being' exhibit pros hen reference to God. It is important to see that the deductions presented in $M e t . \Lambda$ are not merely dialectical, i.e. proceeding from reputable opinions to some probable truth; they are demonstrations because they prove properties of the subject-matter of the science (Theology) itself in the same spirit that Euclidean geometry demonstrates the properties of triangles and circles. These demonstrations are the beginnings of the universal science that Aristotle began looking for in Met. $\Gamma$ 2.

In Met. $14 \& 5$ Aristotle shows that the notions of substance, actuality, and unity are insufficient as principles, when considered analogically, because they differ in application to things located in different contexts. Aristotle requires permanent existence. And he does not stop until he finds a Prime $\operatorname{Mover}(\Lambda 5,107$ 1a29) who remains the same for all things in all contexts.

Substance, actuality, and unity represent Aristotle's three layers of focal analysis of the term 'Being'. These three aspects are found among what I take to be Aristotle's "principles and highest causes of beings" (1003a26); so that the Metaphysics constitutes not only a series of dialectical responses to the questions raised in Book B, a search for a suitable focal meaning for 'Being', but also a search for the principles and highest causes of Being. I locate five groups of highest principles and causes in the Metaphysics:

I. Principles common to all science: (1) the common doctrines (i.e. necessary logical laws of noncontradiction (1005bl8-25), identity (1003a22-33), and excluded middle, $101 \mathrm{lb} 23-29)$, v. Met. $\Gamma$, chh. 38 ;

II. Principles unique to first philosophy:

A. Theological:

(2) God, "that which imparts motion without being 
moved, being eternal, substance, and actuality" (1072a25), v. Met. $\Lambda$, chh. 6-10.

B. Ontological:

(3) Elements of Substance (1070bl6-21): form , privation, and matter, v. Met. $Z$, chh. $1-17 ; /$, chh. 1-6; 7 1-5;

(4) Modalities of Being: actuality and potentiality, v. Met. $\Theta$, ch. $5 ; 5$, chh. $8-10$; and $\Lambda$, ch. 5;

(5) The Primary Differences and Contrarieties of Being (106/a 12): One v. Many opposition and their categorical manifestations in Same $v$. Other (difference in Quality), Equal v. Unequal (difference in Quantity), and Like v. Unlike (difference in Relation), v. Met. $\Gamma$, ch. 2; 3, chh. 1-10; K, chh. 2-3.

In Book $\Lambda$ Aristotle argues that groups (3), (4), and (5)substance, actuality, and unity - are to be found in the highest degree in the Prime Mover. The concepts of "ontology" gain scientific legitimacy by being deduced as properties of God, and thus recycled in "theology."

The "common doctrines" of group (1), says Aristotle (Met. $\Gamma$ $3,1005 b 5)$, must be studied by the philosopher because they represent the starting-points for all syllogistic reasoning:

And so it is clear that it naturally belongs to the philosopher who theorizes about all substance to investigate also the syllogistic principles; and it befits the man who knows most about each genus to be able to state the best established principles of his subject; so that the man concerned with beings qua beings should be able to state the most established principles of all things. And this man is the philosopher (my translation Metaphysics $\Gamma$ $3,1005 b 5-11$ ).

Substance, actuality, and unity represent different currents of focal analysis. The common doctrines are not part of this kind of analysis. 
The philosopher studies such doctrines because they must be established before intelligible discourse on any subject can begin. This includes discourse over the nature of substance, actuality, and unity. In Metaphysics $14 \& 5$ we see a fundamental reassessment of the leading contenders for first principle and cause of all beings. These contenders were primary substance (and its elements form, matter, privation), intelligible being and unity, along with actuality and potentiality. Aristotle intends to show in $\Lambda$ that the principles and elements of beings previously considered are each insufficient as first principles for various reasons. There is clearly a dialectical tension in $\Lambda 4 \& 5$ produced by the fact that the previous contenders provide, through analogy, an intelligible basis for conceiving the Being of all there is, but not a separately existing ideal basis of permanence. Aristotle's focal analysis has led him into a search for an entity that would provide an objective basis of sameness and permanence for all there is in the universe. Unity, actuality, substance may be sufficient to describe this entity analogically, but they are merely intelligible universals acquired by analogy. They do not carry a separate nature the same for all things, except as attributes of God.

Here is a summary of Aristotle's $14 \& 5$ reassessment of his previous currents of focal analysis of 'Being':

(1) The argument against being and unity as principles

The intelligible universals being and unity cannot be principles and elements of things common to the several categories and prior to them, because (a) no element can be the same as the complex which includes it, and (b) being and unity are predicable of concrete things. Presumably, because the intelligibles, being and unity, are not substrata for predication, they are dependent upon the existence of some other thing (an individual like Socrates or a species) to serve as substratum. The substratum grounds the intelligible form much the way God grounds intelligible being and unity (cf. Met. 1070a35-b10).

Aristotle has just begun (1070a36-1070b4) his search for a cause common to both relations and substances. This common cause would be applicable universally across categories. But even the most universal of intelligibles, being and unity, do not 
possess by themselves the kind of independent existence that such a cause requires; if they did, they would be Platonic Forms:

Furthermore, in what manner is it permissible for the elements of all things to be the same? For no one element can be the same as that which is composed of elements; for instance, ' $B$ ' or ' $A$ ' cannot be the same as their composite 'BA'. Nor, therefore, can any of the intelligibles, e.g. being and unity <serve as an element of things>; for these are predicable of each thing, even of composites (Metaphysics 14, 1070b4-8, my translation, Ross ed.).

Being and unity can not be the common elements of things by themselves because they are predicable of concrete things; they are predicated of each entity, even of composites - $\dot{u} \pi \dot{\alpha} \varrho \chi \varepsilon \iota \gamma \grave{\alpha} \varrho$

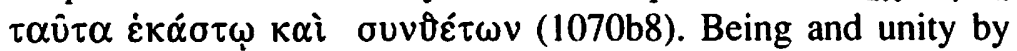
themselves are not things of which concrete things would be predicated; it is not the case that "Socrates is Being" and "this reed stalk is Unity." These predicates depends upon a subject; and this subject can only be God. The undercurrent here is that the intelligibles, being and unity, must have existence in the composites of which they are predicable; since they can not exist as separate, freely-floating Platonic Forms. Being and unity are neither Forms nor concrete substrata for predications; if they were, Aristotle would no longer need to search for a real basis of permanence in the cosmos.

(2) The argument against form, matter, and privation as principles

Because all sensible things have a form (e.g. heat), a privation (e.g. cold), and a matter, we can know by analogy that the elements of substance - form, matter, and privation - are the elements of all things; but, unfortunately, even these are different across genera (Met. 1070b9-21).

Again, just like being and unity, the elements of substance are only common features of all things when considered analogically. In reality they differ across genera; that is, the form, privation, and 
matter for triangles, animal bodies, and celestial spheres is different for each genus, but, by analogy, the same:

Or as we say, there is a sense <in which the elements of all things are the same $>$, and a sense $<$ in which they are $>$ not $<$ the same $>$. For instance, perhaps heat is the form of sensible bodies while cold is their privation, and matter is that which directly, in virtue of itself, is potentially these, while these <elements> along with the things composed of them, whose principles are these <elements>, are substances; i.e. any unity which comes to be from heat and cold, e.g. flesh and bone; for it is necessary for that which comes to be to be distinct from these. Now then the elements and principles of these things are the same (though different for different things), and it is not possible to speak of all things in this way, but <it is possible> by analogy-just as if someone were to say that the principles are three in number, the form, the privation, and the matter. But each of these is different for each genus. For instance, in color these are white, black, and surface-or again, light, darkness, and air, for from these come day and night (Metaphysics $\Lambda$ 4, 1070b10-21, my translation, Ross ed.).

The elements of substance take on different realizations in different contexts; and so, are not absolutely the same for all things. For instance, color is a genus comprising a continuum of varying degrees of color. There are extremes at both ends of the continuum, but there is also an intermediate. The matter in which the contrary extremes pass into and out of existence is surface, i.e. any surface of any object. The form - privation - matter sequence is played out differently in different genera. The genus human body comprises the contrariety of hot and cold. And the matter in which these contraries are found constantly replacing each other is, as Aristotle says, flesh or bone. It is tempting to think that Aristotle 
wishes to get rid of form, privation, and matter (along with being and unity) because of their variability in application to things. But this would be a mistake. Aristotle wants to save them by finding an entity which would exemplify the principles of substance and unity in the highest degree by serving as a basis of permanence for everything in the cosmos.

(3) The argument against actuality and potentiality as principles

By analogy, says Aristotle, the principles of things are the same, for instance, actuality and potentiality; but these too, like form, privation, and matter, are different for different things in different circumstances (Met. 107la3-11). By analogy actuality and potentiality are principles. But, once they are applied to a host of real objects existing in different genera, they fail as common factors because they lack the separate existence required to allow them to function as ontological points of reference for all things potential and actual. Notice at the beginning of the following passage the recurring theme of substratum $v$. predicate. The latter depends upon the former; if we are to grasp the principles and elements of things these must be independent in existence. Affections and movements do not exist without substances. And analogical notions like actuality and potentiality depend upon the substrata of which they are predicable. There is a sharp division between permanence and change in the following passage. The soul and body, or, alternatively, the intellect, desire, and body (1071a3), are suggested as permanent principles. But, again, affections and movements of substance, actuality and potentiality differ from entity to entity:

Since, on the one hand, there exist separate entities, and, on the other, non-separate entities, the former will be substances. And for this reason the causes of all things will be the same, because, without substances, affections and movements would not exist. Perhaps then these will be soul and body, or intellect, desire, and body. And yet in another way, by analogy, principles are the same; for instance, actuality and potentiality. But these are different for different things in different 
contexts. For in some cases the same entity will at one time exist in actuality and at another time in potentiality; e.g. wine or flesh or man. (And these fall under the aforementioned causes; for, on the one hand, both the form-if it is not separate-and the composite, and the privation (e.g. darkness or sickness) exist actually, but the matter only potentially; for it represents the potentiality for becoming both. But the distinction between actuality and potentiality assumes a different shape for things whose matter is not the same and whose ${ }^{19}$ form is not the same but different; just as the elements serve as the cause of a man-fire and earth as matter along with an individual form - and, in addition to these, something else outside, e.g. the father, and besides these the sun and its slanting orbit, these being neither the matter, nor the form, nor the privation, nor the same species as man, but rather moving causes (Metaphysics $\Lambda$ 5, 1070b36-1071a17, my translation, Ross ed.).

Aristotle is searching for a substantial permanence to physical change. He even briefly speculates that perhaps this substantial basis of permanence is soul and body, or perhaps intellect, desire, and body. In $\Lambda 6$ he concludes, however, that there must be an eternal prime mover. The motivation seems to be that in too many cases the same thing is both actual and potential. E.g. Socrates is potentially whatever he is when considered according to matter, but actually whatever he is when considered according to form. That is, different aspects of the same substance are at the same time actual (as form) and potential (as matter). Furthermore, when cause and effect have not the same matter the distinction between actuality and potentiality differs dramatically. The father of Socrates is a moving cause which has a different parcel of matter than the sun, which is another moving cause. The sun and the ecliptic are neither Socrates' matter, nor his form, nor the privation of that form; they are remote moving causes which allow Socrates 
to flourish in life. So, perhaps, it is not even accurate to limit the elements and causes of Socrates to just the matter, form, and privation present in his person. But if so, where does the regress of outside causes and principles cease? Aristotle's point here is that actuality and potentiality differ when applied to individuals in different contexts. He seems to question the objectivity of these notions. If they differ in different circumstances, how can they serve as standards of knowledge? Aristotle seeks something that will remain the same in reference to any thing in any context. The passages we have looked at from Metaphysics $\Lambda 4 \& 5$ make the radical suggestion that all previous efforts expended in the dialectical search for the principles and starting points of existence have been in vain; for none has brought the philosopher to a separately existing, self-sustaining, substantial basis of permanence in the universe.

Each of the three arguments from Met. $\Lambda$ chh. $4 \& 5$ are designed to show that the principles he thought to be universally applicable to all beings by analogy, are really not the same for all because they lack permanent independent existence. They are just as suspect to criticism as Platonic Forms because they too lack a principle productive of movement and change. In short, we need a separate and permanent entity that is common across genera, and is at the same time productive of cosmic movement. The intelligibles being and unity, the elements of substance, and actuality \& potentiality do not satisfy the requirement of separate existence across genera; for things in different genera manifest different kinds of matter, different kinds of unity, and so forth. Only an eternal substance, whose existence is proven at 1071b3-12, satisfies both of these requirements in full.

Aristotle's ontology, i.e. his study of the various senses of "Being" ends in Met. $\Lambda$ ch. 6 where he begins to demonstrate certain properties of the divine nature. The trend in recent scholarship is to treat Book $\Lambda$ a separate treatise on the divine nature; so that Theology may be cleanly separated from Ontology. But such treatment belies the fact that Aristotle's God, as a ideal basis of cosmic permanence which realizes itself in the being of things, stands at the end of his dialectic of senses as the only suitable focal entity. First Philosophy is Theology; for, in studying the nature of 
the divine, one thereby studies that in reference to which all other things are called "beings."

\section{Bibliography}

Anton, John P. Aristotle's Theory of Contrariety. London, 1957.

Barnes, Jonathan. The Complete Works of Aristotle. 2 vols. Princeton, 1984.

Bonitz, Hermann. Index Aristotelicus. (Fifth Edition). Berlin, 1870. Reissued 1955.

Cherniss, Harold F. Aristotle's Criticism of Plato and the Academy. Oxford, 1944.

Irwin, T. H. Aristotle's First Principles. Oxford, 1988.

Irwin, T. H. 'Homonymy in Aristotle', The Review' of Metaphysics, vol. XXXIV, no. 3, March 1981, 523-544.

Jaeger, Werner. Aristotle: Fundamentals of the History of His

Development. Richard Robinson tr. Oxford, 1948.

Jaeger, Werner ed. Aristotelis Metaphysica. Oxford, 1957.

Kirwan, C. A. Aristotle: Metaphysics Books $\Gamma, \Delta$, and E. Second Edition.

Oxford, 1971.

Leszl, Walter. Aristotle's Conception of Ontology. Padova, 1975.

McInerny, Ralph. 'The Science We are Seeking' Review of Metaphysics, vol. XLVII, no. 1, September 1993, 3-18.

Nussbaum, Martha ed. Logic, Science, and Dialectic (Essays of G.E.L. Owen). Ithaca, 1986.

Owen, G.E.L. 'Logic and Metaphysics in Some Earlier Works of Aristotle', Studia Graeca et Latina Gothobırgensia, Düring ed. Almquist \& Wiksell, 1960.

Owens, Joseph. 'An Ambiguity in Aristotle, EE VII 2 1236a23-4' Apeiron, vol. XXII, no. 2, June 1989, 127-137.

Owens, Joseph. 'Is There Any Ontology in Aristotle?' Dialogue, vol. XXV, no. 4, Winter 1986, 697-707.

Owens, Joseph. 'The Grounds of Universality in Aristotle' American Philosophical Quarterly vol. 3, no. 2, April 1966, 162-169.

Owens, Joseph. The Doctrine of Being in the Aristotelian Metaphysics. Toronto, 1951.

Ross, W. D. Aristotle's Metaphysics: A Revised Text with Introduction and Commentary. (2 vols). Oxford, 1924.

Ward, Julie K. 'Focal Reference in Aristotle's Account of M481": Eudemian Ethics VII 2' Apeiron, vol. XXVIII, no. 3, September 1995, 183-205. 
Witt, Charlotte. Substance and Essence in Aristotle: An Interpretation of Metaphysics VII-IX. Ithaca, 1989.

\section{Notes}

'This and all subsequent translations of Aristotle's Greek are my own, unless otherwise indicated.

'Ralph McInerny interestingly divests study of Being from the rigorous requirements of demonstrative science outlined in the Analytics because he, like St. Thomas, wants to see it as the ruling science, and hence as excepted from the parameters governing the ruled sciences; see Review of Metaphysics 47 (September 1993): 3-18. There is, however, no textual evidence that I know of which shows that Aristotle changed these parameters in order to suit ontology because he regarded it as the master science. Being is no genus to be sure. But God is a particular individual substance with deducible properties. In fact, there are a plethora of deductions proving the eternity, actuality, and unity of God in

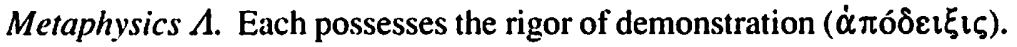
In Posterior Analytics I, 13 Aristotle regards knowledge of the that to be demonstrable as he does knowledge of the why or reasoned fact (cf. 78a30 and 36). St. Thomas believed that the existence of God could be proven by His effects, through demonstratio quia-i.e. proof of the fact that $\mathrm{He}$ exists where the middle term is more known to us-but never (as Euclid proves his several propositions) through first causes, by demonstratio propter quid-i.e. proof of the reasoned fact where the middle term is more known by nature, i.e. rests on an axiom or definition more known than and prior to the conclusion.

${ }^{3}$ T. H. Irwin, Aristotle's First Principles, p. 500, 3n8. C. A. Kirwan would disagree: "[The idea that no science can have all existing things as its subject because of the multiple senses of 'exist'] is suggested by an analogy between 'thing-that-is' and 'good' which Aristotle draws at Nichomachean Ethics I 6. 1096a29-34, where he argues against Platonists that different kinds of knowledge or expertise are required to discover e.g. what is good in war and what is good in medicine: there could not be such a thing as a general knowledge of what is good which would shortcut these particular studies. But it is a mistake to suppose that this analogy raises a difficulty in the way of the inquiry examined in Metaphysics $\Gamma$. The question about existence which parallels the Platonic question 'what is good?' is 'what exists?'; and, while it is true to say that there is no single discipline that includes answers to such questions as 'do electrons exist?' and 'does conscience exist?', metaphysics, according to Aristotle's 
conception of it, makes no claim to be such a discipline. It seems, then, that Aristotle was troubled by a needless anxiety. No danger lurks in his concession that the senses of 'be' are multiple, if that concession is based on the analogy between 'thing-that-is' and 'good'", Aristotle's Metaphysics Books $\Gamma, \Delta$, and $E$, p. 80.

'G. E. L. Owen, 'Aristotle on the Snares of Ontology', Logic, Science, and Dialectic, collected papers in Greek Philosophy by G. E. L. Owen, Martha Nussbaum, ed.

${ }^{5}$ Sophistici Elenchi, I. 9, 170a20-23, Ross ed.

${ }^{6}$ G. E. L. Owen 'Logic and Metaphysics in Some Earlier Works of Aristotle', Düring ed. Studia Graeca et Latina Gothoburgensia, no. 11, 1960, p. 164.

'For a lengthier treatment of the dynamics of focal meaning analysis see T. H. Irwin, 'Aristotle on Homonymy' Review of Metaphysics, 1981 vol. 34, pp. 523-44. And Julie K. Ward, 'Focal Reference in Aristotle's Account of $\Phi$ i $\lambda$ i $\alpha$ : Eudemian Ethics VII 2' Apeiron, pp. 183-205.

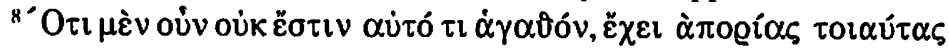

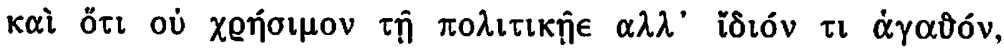

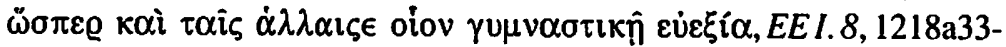
36 , Rackham ed. Aristotle wants to show here that the Good-in-itself has no practical value in political science. Each science is useful because it produces its own peculiar good. Thus, I translate "Such are the difficulties showing that there exists no Good-in-itself, and that it is not useful for political science, but that there exists instead only a peculiar good, just as the other sciences <have their own peculiar goods>; for instance, the <peculiar good> of gymnastics is physical health."

'Ibid., Owen, (Düring 1960), p. 181.

'Ibid., Owen, (Düring 1960), p. 170.

"Cf. Joseph Owens, 'Is There Any Ontology in Aristotle?', Dialogue, vol. XXV, no. 4, Winter 1986, pp. 697-707.

${ }^{12} \mathrm{~T}$. H. Irwin rejects universal ontology in Aristotle because Being, since it is not a genus (as often emphasized by Aristotle himself, esp. Met. 998b22-27, 1053b22-23; Top. 144a36-b3), lacks the kind of $\kappa \alpha 0^{\circ}$ $\ddot{\varepsilon} v$ unity Irwin supposes as requisite for first-order scientific treatment (Ibid. Irwin, ch. 8.86 p. 161). Charlotte Witt follows Irwin closely on this point in Substance and Essence in Aristotle, p. 28. Walter Leszl seems to anticipate both views, Aristotle's Conception of Ontology, p. 175). All three, as we have seen, implicitly deny any universality beyond the categories.

${ }^{13}$ My translation covers Delnt. 16b22-25, Minio-Paluello ed.: oủ $\gamma \grave{\alpha} \varrho$

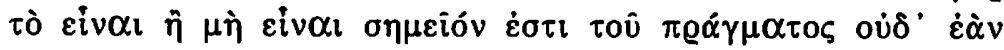




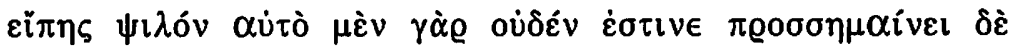

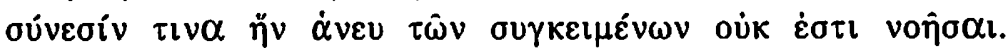

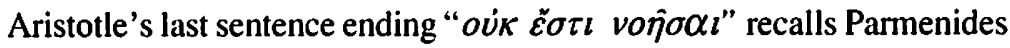
both metrically and philosophically (Diels-Kranz Fragment B 2.2): $\dot{\alpha} i ̈ \varepsilon \varrho$

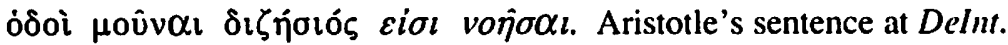
$16 \mathrm{~b} 25$ ends, like a typical hexameter line, with a dactyl and a final spondee. Beginning a prose sentence with the end of a hexameter verse is acceptable, but never ending a sentence; unless one wishes to emphasize a special point or allude to someone else. This rhetorical fine point is found in Dionysius of Halicarnassus, de Thucydide where Thucydidean prose rhythm is discussed. Aristotle's denial of the existence of unqualified Being also responds to Parmenides' two paths of thought: namely, (1) that Being exists, and that it is impossible for it not to exist ( $D K F r . B$ 2.3) and (2) that Being does not exist, and that it is necessary for it not to exist (DK Fr. B 2.5). The latter path is, of course, not feasible for Parmenides because "neither can you come to know non-Being (for this is not to be accomplished), nor can you utter it" $D K F r . B$ 2.7-8. Aristotle clearly disavows the former path, since "to be" functions in thought only by connecting subject and predicate in a kind of semantic synthesis, or in the completion of a verbal idea.

${ }^{14}$ Metaphysics $\Gamma, 1005 \mathrm{a} 3-5$.

${ }^{15} \mathrm{C}$. A. Kirwan, Aristotle: Metaphysics Books $\Gamma, \Delta$, and $E$, Oxford, 1971, p. 85.

${ }^{16}$ Metaphysics $\Lambda, 1075 \mathrm{a} 25$.

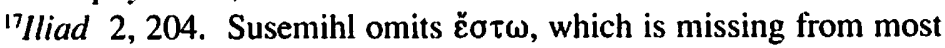
MSS. But as Ross remarks (vol. 2, 405) it would be particularly easy for the last word of a book to drop out in the archetype.

${ }^{18}$ The privations corresponding to the positive notions of substance, actuality, and simplicity (i.e. intrinsic unity) are, presumably, accident, potentiality, and multiplicity (i.e. intrinsic plurality). These privations are not part of the Divine nature.

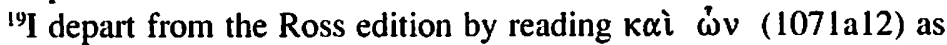
found in the commentary of Themistius, instead of $\dot{\omega} v\langle\dot{\varepsilon} v i \omega v\rangle$. 